\title{
¿Nuevos acentos en la cooperación entre China y América Latina - Una oportunidad para América Latina salir de la "trampa de desarrollo"?
}

New accents in cooperation between China and Latin America - An opportunity for Latin America to get out of the "development trap"?

Novos sotaques na cooperação entre China e América Latina - Uma oportunidade para a América Latina sair da "armadilha do desenvolvimento"?

1. Prof.Dr., politólogo, Ex-Director del GIGA Instituto de Estudios Latinoamericanos en Hamburgo, desde 2018 Independent Scholar, Berlin, Número ORCID: https://orcid.org/0000-0003-0101-1222.

E-mail: kbodemer@t-online.de- (iD
Klaus Bodemer'

DOI: 10.5752/P.2317-773X.2020v8.n3.p174

Recebido em: 26 de novembro de 2019

Aceito em: 27 de julho de 2020

\section{RESUMEN}

Partiendo del nuevo mapa geopolítica y - económica mundial, el artículo pregunta si la creciente cooperación entre China y los países al Sur del Rio Grande ofrece a la región la oportunidad salir de la trampa de desarrollo de su modelo extractivista, vigente desde la época colonial hasta la presente, e insertarse más activamente en la economía y política mundial. Recapitulamos por este fin en una primera parte el auge espectacular de China desde el aislamiento en la era Mao Tsetung hasta el "opening up". En la segunda parte analizamos con más detalle el cambio de rumbo de la estrategia de desarrollo bajo la presidencia de $\mathrm{Xi}$ Jinping y sus reflejos en las relaciones con América Latina, en un contexto hemisférico, caracterizado por un creciente desinterés del gobierno norteamericano en la región. Finalmente discutimos las consecuencias de la oferta china para América Latina y su inserción internacional bajo el el hilo conductor de un desarrollo sustentable. Desde el punto de vista teórico recurrimos a planteamientos del inter- / transregionalismo, del neo-realismo, el social-constructivismo y el concepto del two level game.

Palabras clave: Globalismo descentrado. Consenso de commodities. Estrategias de desarrollo chinas. Relaciones chino-latinoamericanas.. Trampa de desarrollo.

\section{AbSTRACT}

Based on the new geopolitical and economic map of the world, the article asks if the growing cooperation between China and the countries south of the Rio 
Grande offers the region the opportunity to get out of the development trap of its extractive model, in force since colonial times until the present, and to insert itself more actively in the world economy and politics. To this end, in the first part we recapitulate the spectacular rise of China from its isolation in the Mao Tsetung era to the „opening up“. In the second part, we analyze in more detail the change of direction of the development strategy under the presidency of Xi Jinping and its reflections on relations with Latin America, in a hemispheric context characterized by a growing disinterest of the U.S. government in the region. Finally, we discuss the consequences of the Chinese offer for Latin America and its international insertion under the thread of sustainable development. From the theoretical point of view, we resort to approaches of inter/ transregionalism, neo-realism, social-constructivism and the concept of the two level game.

Keywords: Decentralized Globalism. Commodity consensus. Chinese development strategies. Chinese-Latin American relations. Development Trap

\section{RESUMO}

Partindo do novo mapa do mundo geopolítico e econômico, o artigo pergunta se a crescente cooperação entre a China e os países ao sul do Rio Grande oferece à região a oportunidade de sair da armadilha do desenvolvimento de seu modelo extrativista, em vigor desde a época colonial até o presente, e de se inserir mais ativamente na economia e na política mundial. Para este fim, a primeira parte deste relatório resume a espetacular ascensão da China do isolamento na era Mao Tsetung para a „abertura“. Na segunda parte, analisamos com mais detalhes a mudança de direção da estratégia de desenvolvimento sob a presidência de Xi Jinping e suas reflexões sobre as relações com a América Latina, num contexto hemisférico caracterizado por um crescente desinteresse do governo dos EUA na região. Finalmente, discutimos as conseqüências da oferta chinesa para a América Latina e sua inserção internacional sob o fio do desenvolvimento sustentável. Do ponto de vista teórico, recorremos a abordagens de inter/transregionalismo, neo-realismo, sócio-construtivismo e ao conceito de jogo de dois níveis.

Palavras-chave: $\mathrm{O}$ globalismo fora do centro. Consenso sobre as mercadorias. Estratégias de desenvolvimento chinesas. Relações entre a China e a América Latina. Armadilha de desenvolvimento

Introducción: la emergencia de múltiples centros de poder sin un liderazgo global

Somos hoy testigos de un vertiginoso proceso de cambios en el ámbito internacional, caracterizado por la emergencia simultanea de múltiples centros de poder con aspiraciones regionales y globales y de la falta de un liderazgo global (STEWART, 2014, pp 5 y s). Vivimos, siguiendo a Ian Bremmer, ni en el mundo G8, ni G20, sino más en el mundo G-Zero (BREMMER, 2013, p.5). Estamos asistiendo al inicio de una nueva época, de carácter más expoliador en términos de derechos y en la que se abre un nuevo escenario a escala regional y global, más atomizado e imprevisible. Es, parafraseando el título de un libro de Ian Bremmer: "Every Nation for Itself" (BREMMER, 2012) - un "mundo no gobernado" (Unruled World) (STEWART, 2014). El centro de gravedad de poder mundial se traslada, paulatinamente, del Oeste al Este_o, más 
concreto, del triángulo, formado por los EE.UU, la UE y Japón a los poderes emergentes del Sur, en primer lugar China y - con distancia India, Brasil y África del Sur y algunos países de "segunda línea" como Indonesia, Turquía, México, Colombia y Argentina (entre otros). Como resultado de este proceso, la brecha de poder que ha servida durante siglos como el fondo para un orden internacional "centro - periferia" se está achicando y va a ser paulatinamente reemplazado por un orden descentrado, en el cual ninguna potencia - y eso es un fenómeno nuevo - o red de potencias es preeminente. Este nuevo mundo tiene el efecto que las diferencias ideológicas entre las grandes potencias se están reduciendo cada vez más y la brecha entre centro y periferia se está achicando (BUZAN, LAWSON, 2014, p. 72). La falta de una alternativa más allá del capitalismo lleva con sigo una cierta convergencia entre los grandes rivales, lo que significa, por ejemplo, que China es en los hechos ni un enemigo ni un amigo de Estados Unidos, la potencia durante décadas dominante, más bien ambas cosas: económicamente un socio y competidor, políticamente un rival. Eso es, siguiendo otra vez a Buzan y Lawson, un buen mensaje. Lo menos positivo es por otro lado el hecho de que, si bien los Estados se apoyan en recursos de poder comparables, estos están incrustados en un amplio espectro de estructuras de gobernanza, lo que coloca en el centro de atención la pregunta cómo se puede gestionar las relaciones entre los cuatro diferentes tipos de gobernanza capitalista: el liberal, el socialdemócrata, el autoritario competitivo y el autoritario estatal (BUZAN, LAWSON, 2014,72). Se trata de una diferenciación de tipo- ideal que se manifiesta en la realidad más bien como un continuum, porque la mayoría de los Estados son en la realidad híbridas, formas mezcladas. La consecuencia del globalismo descentrado en un mundo de un capitalismo universalizado es que no existe una visión única sobre la combinación de sus tres componentes: el capitalismo industrial, los Estados racional-burocráticos y las ideologías de progreso. Cada de las cuatro variantes de capitalismo ofrece otras respuestas y cada variante tiene ventajas y desventajas/debilidades con respecto a los objetivos perseguidos: eficiencia, bienestar con equidad, estabilidad política, y cohesión social (véasen los detalles al respecto en BUZAN, LAWSON, 2014, pp.78-83). La mayoría de las agencias multilaterales, también aquellas bajo leyes internacionales, carecen de poder real para forzar el cumplimiento con decisiones colectivas. Lo que vale como gobernanza es, por lo tanto, un grosero patchwork de instituciones formales e informales.

Las dinámicas principales en el orden mundial emergente de un globalismo descentrado son el relacionamiento entre formas competitivas de gobernanza capitalista y la reconfiguración del Sur Global (WOERTZ, 2016). Puesto que todas las potencias capitalistas tienen el interés que la economía mundial sigue funcionando, sus relaciones mutuas van a ser tanto cooperativas como competitivas. En las palabras de Buzan y Lawson. "While capitalism has become the only game in town, no single form of capitalism has sufficient legitimacy or power to assert hegemony. Indeed, any attempt to do so is likely to see everyone lose" (BUZAN, LAWSON, 2014, p. 91). 
Enfoques analíticos

Partiendo del posicionamiento de América Latina como actor colectivo en este contexto internacional, preguntamos en los párrafos siguientes si la creciente cooperación entre China y América Latina, fruto del auge del dragón asiático en las últimas décadas y sus cambiantes estrategias de desarrollo, ofrecen a la región la oportunidad salir de la trampa de desarrollo de su modelo extractivista, vigente desde la época colonial hasta la presente, e insertarse más activamente en la economía y política mundial. Recapitulamos por este fin en una primera parte estenográficamente el auge económico espectacular de la potencia asiática en las últimas décadas. Un interés particular merece al respecto el cambio de rumbo de la estrategia de desarrollo interno bajo la presidencia de Xi Jinping y sus reflejos en las relaciones con América Latina en un contexto hemisférico, caracterizado por un creciente desinterés del gobierno norteamericano en la región. En estas relaciones multiniveles nos interesa en primer lugar aquellas de tipo inter- o transregional, documentadas y divulgadas en diferentes strategy papers por el gobierno chino ${ }^{2}$. Finalmente discutimos las consecuencias estratégicas de la oferta multinivel y multisectorial china para América Latina y su inserción internacional activa bajo el hilo conductor de un desarrollo sustentable.

Desde una perspectiva teórica nos sirven en primer lugar variables de cuatro ofertas analíticas de la subdisciplina Relaciones Internacionales: el neorealismo que parte del supuesto de un sistema internacional anárquico y de juego de suma cero, donde las unidades de acción son estados nacionales soberanos cuyos objetivo general es el mantenimiento de seguridad, tanto militar, como económica y social (como instrumentos de poder blando, soft power) y cuyos principios de acción son caracterizados por la perspectiva de poder, los intereses nacionales y el equilibrio, la competencia, la formación de bloques y conflictos económicos (MORGENTHAU,1948; WALTZ, 1979) ${ }^{3}$. El segundo enfoque es el inter- o transregionalism, una forma específica del bi-regionalismo, que puede cubrir diferentes formas de política exterior de un régimen regional (véanse al respecto HÄNGGI, 2006, pp.1-62). En nuestro caso interesa la variante de cooperación de América Latina como actor colectivo (Comunidad de Estados Latinoamericanos y Caribeños / CELAC y el Foro China-CELAC), un grupo de países (por ejemplo Mercosur, la Alianza del Pacífico, AP) o el mecanismo de Cumbres con una potencia externa, en nuestro caso, China. Un tercer concepto valioso para comprender mejor el objeto de nuestro estudio es el social constructivismo que comprende la realidad internacional, en nuestro caso, las relaciones entre América Latina y China, como una construcción social, como un proceso contingente, abierto a la transformación. El concepto parte del presupuesto que lo que comprendemos como "realidad" no se manifiesta por su misma, es más bien siempre construida por la manera como actuamos con otros, cuales son percepciones comunes sobre el mundo y como experimentamos nuestro ambiente. Relaciones internacionales son, por lo tanto, según este enfoque en gran parte constituidas más allá de factores materiales por factores inmateriales como ideas, normas, identidades, son procesos comunicati-
2. Un análisis detaillado de la cooperación chino con los países particulares en América Latina excedería el marco de este artículo.

3. Este enfoque es más idóneo para el análisis del comportamiento de un sistema centralista y autoritario como el chino que para regímenes democráticos con su pluralismo de actores políticos y veto players. 
4. Sé que la calidad de América Latina como actor colectivo en el ámbito internacional, su actorness, es muy reducida y se restringe en gran parte al nivel discursivo y simbólico. Sin embargo, los diferentes poliy papers del gobierno chino, que describen la estrategia china hacia América Latina se dirigen a América Latina como región. Actores latinoamericanos de peso que disponen realmente sobre los recursos materiales e inmateriales necesarios para actuar globalmente son de hecho en América Latina solo Brasil y México (al respecto véase BODEMER, 2019) vos, caracterizados por discursos y convicciones (WENDT, 1999; ONUF, 1989; MÜLLER, 1994)

Los cuatros conceptos analíticos no son excluyentes, iluminan y hacen comprender más bien diferentes aspectos de la realidad que analizamos. El interregionalismo es, por ejemplo, como Gilson ha subrayado, una construcción sociopolítica, constituida por interacciones interregionales desarrolladas a través de la comunicación mutua y la percepción del "otro" (GILSON, 2005) Los argumentos realistas y neorealistas se centran en el poder y el equilibrio como características esenciales de las relaciones inter - y transregionales. El enfoque constructivista busca, finalmente, los efectos indirectos, el aprendizaje institucional y los factores cognitivos que explican la construcción de la identidad del actor colectivo y de su contraparte y sus proyecciones exteriores.

\section{El posicionamiento actual de América Latina en el ámbito internacional}

Tomando en cuenta la geografía política y económica, anteriormente esbozada, ¿Dónde se encuentra América Latina?4 No hay dudas que la región ha consolidado durante los últimos quince años su posición en un escenario internacional caracterizado por la crisis o el estancamiento de las economías más industrializadas y el auge de los países emergentes del Sur. El Leitmotiv de esta etapa es el llamado "Consenso de Commodities", percibido como una alternativa al "Consenso de Washington" de Estados Unidos (RAMO, 2004) y basado en la exportación de bienes primarios a gran escala. El interés de China se concentró al respecto en megaproyectos extractivos (mega-minería, explotación petrolera), la construcción de mega-represas y el nuevo capitalismo agrario con su combinación de transgénicos y agro-tóxicos, entre otros. La capacidad de crecimiento de América Latina es hoy condicionada por una restricción externa derivada de las limitaciones para financiar la inversión y recurrentes crisis de balance de pagos. La participación de la región en las exportaciones mundiales de bienes y servicios y las cadenas de valor permanece estancada y su cuota en los intercambios de bienes de alta tecnología y servicios modernos sigue siendo reducida. A pesar de ciertos logros que se observan respecto al contenido de tecnología y conocimiento de las exportaciones, estos avances no alcanzan para permitir acortar las brechas de productividad que separan a las economías de la región de los mercados más competitivos (KACEF, BALLESTRY, 2014). La integración regional, tanto de los regímenes tradicionales (Mercosur, Alianza Bolivariana para los Pueblos de Nuestra América /ALBA; Comunidad Andina), como el llamado "regionalismo autónomo latinoamericano" o "regionalismo desafiante" (CELAC, Unión de Estados Suramericanas /UNASUR) (PRECIO CORONADO, 2013) está estancada o en plena crisis. Los nuevos gobiernos de centro-derecha o derecha priorizan, como el actual gobierno norteamericano, el bilateralismo. En resumen, una presencia regional coherente y concertada de América Latina en la arena internacional (y hacia China) parece hoy más lejana que nunca. Plataformas de concertación como la CELAC y el Foro China-CELAC son intentos para corregir estos déficits, sus alcances, sin embargo, frente a la creciente fragmentación de la región más bien modestos. 
El auge espectacular de China - del aislamiento al "opening up"

Uno de los fenómenos geopolíticos y geoeconómicos más espectaculares de las últimas décadas es sin duda el auge de China. Podemos distinguir al respecto desde el cambio del siglo y siguiendo a Myers, tres etapas (MYERS, 2016, p. 28; GALLAGHER, 2017 distingue 5 fases). La primera comienza con la post-Mao agenda, llamada "reforma y apertura" ("reform and opening up)" que fue implementada en el año 1978/79 por Deng Xiaoping e incluyó la introducción incremental de principios de mercado y un (aún moderado) compromiso internacional. Durante las cuatro décadas antes de Deng, la República Popular de China fue, vista desde afuera, prácticamente inexistente. Su output económico fue más modesto que aquel de países mucho más pequeños, por ejemplo España o los Países Bajos. Empresas privadas fueron prohibidas en la economía, centralmente planificada antes de $1978^{5}$. Deng inició una serie de profundas reformas económicas, sociales y políticas y lanzó su programa de las Cuatro Modernidades (Agro, Defensa Nacional, Industria y Ciencia y Tecnología). Las unidades productivas ganaron mayor autonomía y el sistema de terminación de precios mayor flexibilidad. Ambos factores fueron claves para el incremento de los niveles de productividad de la industria en China. Las medidas de reforma fueron acompañadas por una creciente apertura comercial y la creación de zonas económicas exclusivas en el este del país, las llamadas Zonas Económicas Especiales (ZEE). Estas zonas recibieron beneficios como exención de impuestos en las producciones destinadas a la exportación, alquiler de terrenos estatales, facilidades para importar subproductos así como garantías de que estar provistos de mano de obra ${ }^{6}$. Como efecto, las grandes transnacionales globales emitieron importantes flujos de IED hacia estas zonas yaqué encontraban convenientes su radicación allí por los bajos costos laborales. El gobierno chino exigió de los inversionistas extranjeros como contraparte la conformación de joint ventures con empresas estatales y una gradual transferencia de tecnología hacia grandes empresas de capital local. Paralelamente, el gobierno chino llevó la reducción de aranceles de un 56\% en 1981 hasta un 11\% para 2003 (SHIRK, 2007).

Las reformas de Deng llevaron a incrementos de productividad laboral por encima de los salarios durante más de 30 años y grandes superávits comerciales, altas tasas de ahorro, una agresiva política de inversión en diferentes regiones del globo e incluso a ser prestamista de muchos países de África y América Latina.

Con los pasos valientes de Deng comenzó el milagro chino. La política de atracción de inversión extranjera se amplió durante los años 90 hacia otras zonas del país con el resultado que en 2015 se encuentra ya en 500 ciudades del país (SEVARES, 2015, p.26). Como consecuencia, la economía china experimentó un crecimiento de dos dígitos durante tres décadas e incluyó la introducción incremental de principios de mercado y un (todavía moderado) compromiso internacional. Deng utilizó la frase de "lo chino para la esencia, lo occidental para lo práctico".

La medidas denguistas - reformas macroeconómicas, desregulación de mercados internos y la apertura a mercados internacionales -
5. Hoy, empresas privadas chinas generan en la "economía socialista de mercado de rasgos chinos" el 60\% del output económico (FUNDACIÒN BBVA, 2010).

6. La provincia de Guangdong fue la que implementó la mayor parte de estas zonas. Shenzen, Zhuhai, Shantou y Xiamen surgieron como proyectos piloto para la reestructuración controlada de la economía china y su transición de una economía planificada a una economía del mercado (PAPP, 2013). 
7. Siguió en 2009 la adhesión del país al Banco Inter-Americano de Desarrollo (BID) lo que le ha posibilidado invertir en grandes proyectos regionales de infraestructura (BIBLIOTECA DEL CONGRESO NACIONAL DE CHILE, 2009). fueron promovidas después por los sucesores de Deng, Jiang Zemin y Zhu Rongij con el objetivo principal conseguir divisas para financiar el programa de desarrollo económico. Las reformas fueron radicalizadas bajo el lema de una "economía de mercado socialista". La cantidad de empresas estatales se redujo sustancialmente, los impuestos a importaciones bajaron. En 1999 fue promulgado la estrategia "going out", apuntando a responder a la creciente demanda interna de recursos naturales, establecer nuevos mercados externos y fortalecer la competitividad de las empresas chinas. Como consecuencia de estas innovaciones estratégicas, las relaciones económicas birregionales expandieron considerablemente durante las décadas 90 y 2000 (detalles en CEPAL, 2008).

La llegada del siglo XXI llevó una serie de cambios y cuestionamientos sobre el papel que China desempeña. Un dato remarcable en este camino fue la adhesión de China a la OMC en $2001^{7}$ con la cual el país adquirió un mejor acceso a los mercados occidentales. Adicionalmente, la demanda china por productos básicos desde América Latina y otras regiones subió cuando nuevas políticas económicas y sociales llevaron a un boom en el área de construcción y la migración masiva de migrantes rurales hacia los centros urbanos. Como consecuencia, el porcentaje de China en las exportaciones latinoamericanas creció de $1 \%$ en 2000 a 7.6\% en 2009 (ROSALES; KUWAYAMA, 2012. MOURON el al., 2016). Las cifras absolutas del avance fueron aún más impresionantes: Mientras el comercio total entre China y América Latina en 2000 va a 10 mil millones de dólares, ascendió a 267 mil millones de dólares en 2013, lo que correspondió a un ascenso de $2600 \%$ (HEINE, 2017). La otra cara del acceso a la OMC fue, sin embargo, que el dragón asiático debía resignar paulatinamente muchos programas de intervención que había utilizado por décadas y adaptarse a las reglas del mercado privado. China se comprometió, en un primer escalón a abrir su sector de servicios y el agrícola a la competencia externa y luego el sector manufacturero. Los efectos de la nueva membrecía de China a la OMC tenían para América Latina efectos ambivalentes. Fue, por un lado, la precondición para el auge espectacular del comercio bilateral que llenó las cajas públicas de los países latinoamericanos, ricos en recursos naturales, con divisas, perjudicó, por otro lado el sector manufacturero de estos países que fueron inundados por mercancías chinas baratas. Victimas al respecto fueron en primer lugar Chile, Argentina y México, tres países con un sector manufacturero relativamente avanzado.

Los cambios estructurales del desarrollo chino desde los años 90 son un ejemplo elocuente de la interrelación estrecha entre política interna y externa, objeto del concepto analítico "juego de doble nivel" (double level game, ) arriba mencionado.

El creciente interés de China por América Latina y su reflejo en las estrategias institucionales hacia la región

Desde la adhesión china a la OMC, América Latina, una región rica en recursos naturales comenzó a interesar cada vez más a líderes políticos y empresarios chinos, a pesar de su gran distancia geográfica. La crecien- 
te importancia de China como potencia emergente en la arena global fue, por otro lado, percibida al otro lado del pacífico por muchos países latinoamericanos como una oportunidad para contra-balancear la influencia norteamericana después de una década de reformas neoliberales basadas en el Consenso de Washington que han llevados a resultados desastrosos. El momento fue oportuno. El nuevo viento en América Latina desde 2003 en adelante, la toma del poder de gobiernos de centro-izquierda e una izquierda populista y la creciente crítica de Estados Unidos a ellos facilitaron maniobras políticas chinas en la región al sur del Rio Grande, permitieron inversiones de transnacionales chinas, abrir canales de cooperación financiera y profundizar el intercambio económico tanto a través de canales oficiales como comunidades chinas en la región. Mientras los latinoamericanos registraron con mucha atención que los chinos han demostrado gran capacidad de implementación de políticas y remarcables éxitos en la distribución de ingresos y la lucha contra la degradación del medio ambiente, los chinos, por su parte, tenían una demanda sin precedentes por recursos naturales y extractivos para mantener las altas cuotas de crecimiento de los últimos años. Sus dirigentes fueron interesados por lo tanto en un acceso amplio a los recursos naturales, minerales y petróleo, de los cuales América Latina dispone ampliamente. Esta constelación de complementariedad entre las dos regiones fue percibida por ambas partes como una situación win-win (CESARIN, 2011, pp.17y s). China invirtió cada vez más en América Latina, aumentó su balance comercial positivo y su influencia en el ámbito internacional, si bien hasta la asunción de Xi Jinping en 2012/13 con un perfil más bien bajo, como Deng ya ha recomendado dos décadas atrás. La estrategia económica hacia afuera fue centrada a aquellos países, que, de acuerdo con la "Tesis de los Tres Mundos" pertenecen al Tercer Mundo, es decir Asia, África y América Latina. Según la retórica oficial, el creciente compromiso en los países al sur del Rio Grande fue meramente un asunto económico sin pretensiones políticas, si bien los líderes chinos vendieron al mismo tiempo el milagro chino como un ejemplo para el mundo subdesarrollado.

El hambre china por materias primas catapultó los precios de muchos de estos productos exportados por la región y revirtió la vieja maldición de la deterioración de los términos de intercambio, según la cual los precios de las importaciones de manufacturas aumentan siempre más que los de las exportaciones de materias primas. China se convirtió desde la segunda mitad de la primera década del siglo XXI en el primer y segundo destino de exportaciones y origen de importaciones de muchos países latinoamericanos. Como resultado, el país asiático es hoy el principal consumidor mundial de productos exportados por América Latina, como trigo, soja, arroz y carne y el segundo consumidor del maíz. Se trata de una demanda que no es coyuntural porque China tiene solo el $7 \%$ de su superficie cultivable, lo cual lo convierte en un demandante estructural y de largo plazo de alimentos. (XINHUA, 2019).

La baja del crecimiento en China desde mediados de la segunda década de este siglo y nuevos acentos en la estrategia de desarrollo chino no significaron que las exportaciones latinoamericanas tradicionales no encuentran un mercado en China pero su importancia está perdiendo 
peso. Una nueva y creciente clase media china está cambiando el perfil del consumo e importaciones. Paralelamente al comercio, los créditos y las inversiones chinas en la región crecieron desde el comienzo del siglo en forma exponencial. A las expectativas económicas se agregaron grandes expectativas estratégicas porque la potencia asiática fue considerada en las capitales latinoamericanas una aliada de los países periféricos, un contrapeso de frente a las potencias occidentales, en primer lugar Estados Unidos, y líder del Sur Global y sus relaciones con América Latina como parte de la cooperación Sur-Sur.

El parte de aguas en las relaciones entre la potencia asiática y América Latina se gestó en el año 2004 con una visita histórica del presidente Hu Jintao a Brasil, Chile, Argentina y Cuba. Como resultado de esta visita, el gobierno chino firmó un memorando de entendimiento con cada uno de estos países, en el cual las naciones sudamericanas le reconocen el estatus de economía de mercado. El impacto de este paso para los países latinoamericanos fue, como Oviedo ha subrayado con razón, ambivalente. Abrió a los países visitados, por un lado, la colocación de sus productos primario-extractivos al mercado chino, basada en el principio chino de "equilibrio positivo"; y como resultado recibir un alto volumen de divisas, también positivo; representó, sin embargo, también "el fracaso de la diplomacia multilateral del Mercosur, el alejamiento del protocolo de adhesión de China a la Organización Mundial de Comercio y la ideología del multilateralismo" (OVIEDO, 2006).

El apetito chino por materias primas para sostener el boom económico y alimentar su población tenía impactos fuertes en algunas economías latinoamericanas. China fue, por ejemplo, ya a mediados de la segunda década de este siglo el segundo mayor mercado de exportaciones de Chile (hoy el primero); el país asiático importó un quinto de su cobre y el $45 \%$ de su vino y sus frutas. Solo Brasil entregó el $45 \%$ de las importaciones chinas de soja. Ya en 2005 , el $80 \%$ de las importaciones chinas de harina de pesca vino de Perú y Chile (ARNSON; MOHR; ROETT, 2011, p.1). Las reservas chinas de monedas extranjeras fueron ya en 2006 las mayores del mundo. En 2010, China adelantó a Japón y fue de aquí en adelante la segunda economía más fuerte en el mundo. Gracias al aumento espectacular del crecimiento, millones de chinos y chinas mejoraron sus condiciones de vida y un grupo significativo y creciente pasó a formar una nueva clase media y un núcleo de millonarios se insertó cómodamente en el sistema gobernado por el Partido Comunista. El creciente compromiso chino en la región fue, por otro lado, también una importante arma de coerción para el reconocimiento del estatus que Beijing ha reclamado con respecto a Taiwán y el carácter asimétrico de las relaciones mutuas.

La creciente cooperación entre China y los países de América Latina y el Caribe ha pasado desde la mitad de la primera década de este siglo por una serie de hitos o fases que caracterizan las estrategias chinas perseguidas hacia la región, expresión de un nuevo inter-o transregionalismo. Documentos institucionales al respecto son: (1) el primer "Libro Blanco" de las relaciones bilaterales en 2008; (2) el Informe sobre Desarrollo Sustentable de las Empresas Chinas en Ultramar en 2015; (3) el Plan de Cooperación 2015-2019, propuesto por Xi Jinping en 2014 durante la Primera Cumbre de 
Líderes de China y América Latina y el Caribe celebrada en Brasil y adoptado en 2015 durante la Primera Reunión Ministerial del Foro de China-CELAC, celebrada en Beijing; (4) el segundo " Libro Blanco" en 2016; (5) La Iniciativa Franja y Ruta (FyR).

\section{El primer "Libro Blanco"}

En 2008, año de los juegos olímpicos en Beijing, el gobierno chino publicó un documento conocido como el Libro Blanco de las Políticas de China hacia América Latina en el cual esbozó su estrategia hacia la región, subrayando la multipolaridad y el desarrollo pacífico y definiendo las áreas prioritarias de cooperación. El documento retoma los "Cinco Principios de la coexistencia pacifica" que caracterizan tradicionalmente las relaciones chinas con otros países y consisten en el respeto por la soberanía e integridad territorial, la no-agresión mutua, la no-intervención en los asuntos internos de ambos lados, igualdad y beneficio mutuo y la coexistencia pacífica.

Desde la divulgación de este documento se intensificaron las giras de altos dirigentes chinos a la región, creció la cantidad de memorandos de entendimiento, el comercio, las inversiones y créditos como los acuerdos de cooperación en materia científica, cultural y otras áreas entre Beijing y países latinoamericanos.

El creciente compromiso internacional y global de la potencia asiática fue vendida bajo los lemas de reciprocidad, el beneficio mutuo y la cooperación Sur-Sur e intentó con eso diferenciarse de las relaciones jerárquicas Norte-Sur de las potencias tradicionales del Norte (MINISTERIO DE RELACIONES EXTERIORES, 2008).

Un rebalanceo del modelo de desarrollo vigente - De la "nueva normalidad" al Informe sobre "Desarrollo Sustentable de las Empresas Chinas en Ultramar".

Con la asunción de Xi Jinping en marzo 2013 y sus iniciativas domésticas e internacionales comenzó una nueva era en la política económica y exterior de China y un rebalanceo de su modelo de desarrollo. Ya la crisis financiera de 2008/09 ha descubierto las debilidades del modelo de desarrollo chino. La fijación extrema a las exportaciones se mostró ahora como el canal central de transmisión de la crisis. (SCHÜLLER; SCHÜLLER-ZHOU, 2009, 167). El crecimiento bajó a finales de 2008 a solo alrededor de $6 \%$ como consecuencia de la decreciente demanda mundial. Xi se despidió como primer paso del decision making consensual de Deng, concentró todo poder político en sus propias manos y abandonó la política exterior de bajo perfil en favor de una que es muy ambiciosa y expansiva.

El nuevo líder promulgó en noviembre de 2013 un amplio programa de reformas económicas que incluyó prácticamente a todos los sectores y significó la despedida del modelo de desarrollo, vigente durante tres décadas. Los crecientes costos de trabajo y la revaluación del Yuán han puesto en riesgo la competitividad de la industria china y motivado a los líderes políticos reemplazar modelo de crecimiento vigente hasta ahora, basada en exportaciones y empujado por grandes inversiones, por una es- 
trategia que apunta a productos con mayor valor agregado, más servicios y una mayor demanda interna.

Temporalmente, estas correcciones estratégicas de la cúpula china fueron iniciados cuando América Latina vivió el fin del llamado "superciclo" de altos precios de los commodities que prevalecieron en la mayor parte del período comprendido entre 2003 y 2011/12. Los países emergentes, ricos en recursos naturales, entre ellos latinoamericanos, perdieron progresivamente posiciones en el mercado mundial. El modelo de su desarrollo, basado en ventajas comparativas tradicionales recursos naturales sin transformar - el cual ha posibilitado un boom económico, amplias políticas sociales y una política exterior pronunciada, no pareció servir más a la región como hilo conductor hacia el futuro.

El cambio de rumbo, promovido por Xi Jinping figuraba bajo el lema de la nueva normalidad (new normal). y circunscribe el proceso de una profunda transformación socioeconómica, la cual tenía el objetivo implementar una ambiciosa agenda de desarrollo para mantener y profundizar el liderazgo en la segunda fase de desplazamiento de la riqueza mundial. Esa estrategia supone una transición de un crecimiento hacia afuera - rasgo que fue iniciado por las reformas de Deng y sus dos seguidores y profundizado desde el comienzo de este siglo- hacia un crecimiento basado en un mayor consumo interno, en el contexto del envejecimiento demográfico, la consolidación de una clase media urbana y un desplazamiento hacia el sector de servicios e industrias intensivas en conocimiento y tecnología. La idea básica fue que China necesita, en lugar de depender de las exportaciones y una economía intensiva de capital, la cual fue acompañada por las distorsiones y desequilibrios, participar en la búsqueda de nuevos "motores" de crecimiento en el contexto de un comercio mundial más balanceado, lo que implica ahorrar menos y gastar más en consumo. (ARBACHE, 2019).

El documento Informe sobre Desarrollo Sustentable de las Empresas Chinas en Ultrarmar de 2015 describió en detalle la nueva estrategia de cooperación externa y mostró que las autoridades chinas están crecientemente conscientes de los impactos medioambientales y sociales causados por mega-proyectos, por ejemplo, en el sector energético. Para hacer sus inversiones sustentables, el informe exhorta a las empresas chinas a desarrollar corporate social responsability en aquellos países donde poseen inversiones. (CHINESE ACADEMY, 2015)

Las nuevas prioridades de desarrollo interno surtían también efecto en las relaciones con América Latina, una región, para la cual el nuevo enfoque de desarrollo chino, centrado en la innovación, significó tanto un desafío como una oportunidad. Tradicionalmente, las relaciones bilaterales entre China y los países de la región fueron marcadas por productos básicos. Con la innovación como centro de la nueva estrategia, este eje podría verse superada o, mejor dicho, complementado por "emprendimientos compartidos" (joint ventures) más propios del siglo XXI, donde la interacción digital abre nuevos horizontes de acción conjunta y permite explorar desarrollos científicos y tecnológicos a distancia y compartir coordinaciones en servicios (REYES MATTA, 2017, p.1). 
El Plan de Acción Quinquenal de China con la región 2015-2019 - La parte operativa de la nueva estrategia

No hay duda, que China esperaba una respuesta integrada de su socio latinoamericano a la nueva estrategia, fue al respecto, sin embargo, más bien frustrado. A pesar de varios intentos profundizar la integración regional, América Latina no dispuso de una agenda regional concertada a pesar de la creación de CELAC en 2010 y cuatro años más tarde del Foro China-CELAC. En el Primer Encuentro de este Foro en enero de 2015 en Brasilia, ambos lados aprobaron el Plan de Acción Quinquenal de China con la región 2015-2019, presentado por Xi Jinping, denominado " $1+3+6$ " (PORTELLES, 2015). El Plan fu promovido en primer lugar por los esfuerzos de los altos mandos chinos en coordinación con la CEPAL y no por un compromiso serio y concertado del lado de los participantes latinoamericanos (REYES MATTA, 2017, p.4). Los tres números "1+3+6" significan un plan, tres motores y seis áreas. Los tres motores son comercio, inversiones y finanzas. En comercio se apunta a elevar el comercio bilateral en 10 años a US\$500 mil millones (2015: 262,2 mil millones) y el stock de inversiones directas a US\$ 250 mil millones (en 2015: US\$ 86 mil millones). Las seis áreas privilegiadas son (1) energía y recursos naturales, (2) infraestructura, (3) agricultura, (4) manufacturas, (5) innovación científica y tecnológica y (6) tecnologías de información (FORO CHINA- CELAC, 2015). Fueron creados para cualquier de estos sectores fondos especiales de muchos millones de dólares. El documento propuso además fortalecer el intercambio con los gobiernos, parlamentos, partidos políticos y autoridades locales por un sistema de becas, visitas e intercambios. Finalmente, el Plan propuso fortalecer la colaboración sobre temas globales en la ONU, la OMC, APEC y el G-20 y subrayó fomentar las relaciones a través del Foro China - CELAC, así como entablar relaciones con organizaciones regionales y subregionales.

Ambos lados parecieron haber encontrado en la CELAC, que excluye expresamente a EEUU, y el Foro China-CELAC por primera vez plataformas y mecanismos de concertación y coordinación subcontinental que permiten que ambos lados se relacionen a través de Cumbres y encuentros entre políticos de alto nivel con otras regiones y foros internacionales con una agenda común - un paso adelante hacia la transformación de América Latina en un actor colectivo y la profundización del interregionalismo. Sin embargo, frente al hecho de que la CELAC careció, a diferencia de la OEA, como plataforma hemisférica de una estructura estable y ha entrado como otros regímenes de integración regional como ALBA y Mercosur en años recientes en una profunda crisis, el tipo predominante de relacionamiento entre China y América Latina fue y sigue quedando por lo tanto el bilateralismo en base de intereses nacionales. Su principal característica es según la nueva estrategia china la asociación, que se diferencia en diferentes status que jerarquizan y por lo tanto diferencian el nivel del vínculo con los socios externos en función de los intereses perseguidos por Beijing en cada caso. Los tipos de asociación tienen por lo tanto un fuerte valor simbólico. Según un análisis del Consejo Argentina de Relaciones Internacionales (CARI) en Buenos 
8. Alicia Bárcenas, Secretaria Ejecutiva de la CEPAL, mencionó como prioridades temáticas la Agenda de Desarrollo post 2015, el futuro régimen multilateral de cambio climático así como la reforma del sistema monetario internacional (CEPAL, 2015)

9. Un anális detallado de las estrategias institucionales de China hacia Latinoamerica, canalizado por el Foro ChinaCELAC y basado en las dos versiones del Libro Blanco (2008 y 2016) y la de la UE por el Foro CELAC- Union Europea se encuentra en MOSQUERA; MORALES RUCALVABA, 2018
Aires, la diplomacia china está diferenciando entre unos catorce status de asociación, los cuales otorga a los países y organizaciones internacionales que considera amigos en el sistema internacional (RAMON BERJANO, 2015, pp. 12-27). En América Latina, por ejemplo, las relaciones con Chile tienen el status de una "Asociación Estratégica", aquellas con Argentina, Brasil, México, Perú y Venezuela el de una "Asociación Estratégica Integral", y las con la CELAC el de una "Asociación Cooperativa" (RAMON BERJANO, 2015, p.15)

Si bien el núcleo duro de la cooperación bilateral entre China y América Latina es económico, ella va más allá de esa e incluye también el área de la cultura y política. Como testigo de esta ampliación puede ser citado, según la CEPAL, el Primer Ministro Li Keqiang quién propuso en su visita en la sede de la CEPAL en junio 2015 que ambas partes exploren un nuevo modelo de cooperación, llamada " $3+3$ ", es decir, la construcción conjunta de tres grandes vías, a) la logística, el área energética y la informática; b) la interacción virtuosa entre las empresas, la sociedad y el gobierno; y c) la ampliación de los tres canales de financiación (fondos, créditos, seguros). China y la contraparte latinoamericana tendrían que fortalecer además según la voluntad de sus líderes su cooperación y concertación en los foros internacionales en temas claves de la agenda global - una propuesta que la CEPAL compartió plenamente ${ }^{8}$.

\section{El nuevo Libro Blanco de 2016}

Un nuevo paso importante en el camino hacia una adaptación de la estrategia de desarrollo y de cooperación con América Latina a los nuevos tiempos fue en 2016 la publicación de una nueva versión del "Libro Blanco" de 2008 con el título "Documento sobre la Política de China hacia América Latina" que manifiesta los objetivos de la política china hacia América Latina y el Caribe y plantea los principios rectores de esa cooperación en las diversas áreas (MINISTRY OF FOREIGN AFFAIRS, 2016). El documento contenía tanto elementos viejos como nuevos, mantiene el reconocimiento de la importancia estratégica de América Latina para el propio proceso de desarrollo y "vende" las relaciones mutuas como una situación win-win para ambos lados. El texto subraya además que la asociación de cooperación integral es caracterizada por tres principios institucionales: flexibilidad, no condicionalidad y multiplicidad, agrega los principios de igualdad, beneficio recíproco y desarrollo compartido y apunta a una alianza global y cooperativa, llevando a las dos partes a una comunidad de futuro compartido ${ }^{9}$. Elementos nuevos son: Primero, el documento toma ahora en cuenta el rol de EE.UU, destacando que las amplias relaciones entre China y la región ni están dirigidas contra, ni excluyen otra potencia. No hay duda que la mayoría de los socios latinoamericanos comparten esa constatación, argumentando que China es lo más tarde desde la crisis financiera de 2008 un socio complementario y no alternativo a Estados Unidos que está ayudando al crecimiento económico de la región y al fortalecimiento de su competitividad a través de inversiones en la infraestructura y la cooperación científica-tecnológica. Segundo, el documento incluyó por primera vez aspectos del desarrollo 
sustentable y respuestas comunes al cambio climático. En el área de la seguridad fue incluido, tercero, la seguridad cibernética - un tema de gran peso también en las relaciones entre EEUU y China - y subraya el interés chino incluir América Latina en el sistema de gobernanza del internet. ((MINISTRY OF FOREIGN AFFAIRS, 2016).

La nueva versión del Libro Blanco es con respecto a sus mensajes centrales muy concordante con el "Plan de Cooperación 2015-2019", establece metas cuantitativas en el área de comercio e inversiones y líneas de trabajo de alto interés para América Latina, como "intensivar la colaboración para promover la industrialización de productos de valor agregado en los Estados miembros de la CELAC" (FORO CHINA- CELAC, 2019). El documento invita a los países latinoamericanos acompañar a China en una política internacional conjunta, en promover la multipolarización, la democracia y el estado de derecho en las relaciones internacionales y aumentar la representación y la voz de los países en desarrollo. Estas líneas generales son especificadas en detalle en las áreas políticas, económicas, culturales, sociales, de paz, seguridad y justicia (VALENCUELA ÁLVAREZ, 2017, pp.128)

\section{El mega proyecto "Franja y Ruta" (FyR) - cooperación Sur-Sur o otra versión de la cooperación Norte-Sur?}

Un pilar adicional de la nueva estrategia china hacia América Latina y con respecto a su dimensión seguramente el más importante es la Iniciativa "Franja y Ruta" (FyR) - en inglés "One Belt One Road",OBOR - que incluye el land-looked "Centurón Económico de la Ruta de Seda" - en inglés Silk Road Economic Belt (SREB) y la "Nueva Ruta de la seda Marítima" - el "Maritime Silk Road" del siglo XXI, un cluster de rutas marítimas que conecta la costa de China al Mar Mediterráneo atravesando por el océano pacífico e india y al lado de una parte de África. Ambas iniciativas fueron anunciadas por Xi Jinping ya en 2013 en Kazajistán, pero oficialmente publicadas en mayo de 2017 en Beijing con la presencia de 27 Jefes y Jefas de Estado. Asistieron de América Latina en este evento el presidente de Argentina, Mauricio Macri, y la presidente de Chile Michelle Bachelet. El proyecto retoma la antigua ruta de la Seda del siglo I a.C. en tiempos de la dinastía Hanson y es un ejemplo más de la diplomacia proactiva y emprendedor de Xi en un mundo multipolar, globalizado y focalizado al desarrollo. El objetivo general es la construcción de nuevos corredores económicos y zonas de libre comercio que se orientarán a largo plazo a estándares chinos (MINISTERIO DE RELACIONES EXTERIORES, 2015). Los chinos nunca han definido que la Iniciativa FyR realmente incluye, pero esa falta de precisión es una característica de la política china en general. Un listado, presentado en el marco del Segundo Foro de FyR en abril 2019 en Beijing, menciona, demostrando sus éxitos, temas tan diferentes como coordinación política, infraestructura, integración financiera y contactos inter-personales. No existe un mapa FyR oficial. En pronunciamientos y declaraciones oficiales se encuentra, sin embargo, un lugar para casi cada país con la excepción de EE.UU., lo que no sorprende frente al conflicto creciente entre las dos potencias hegemónicas y la reacción sensible de Washington al reclamo chino de ser reconocido como un líder global. 
La FyR plantea generar oportunidades en varios sectores, no obstante, su núcleo son proyectos de infraestructura de gran escala para conectar Asia, Europa y África con el fin de impulsar el crecimiento económico y la cooperación internacional. La parte operativa contempla grandes corredores, la construcción de carreteras, líneas de ferrocarril, oleoductos y puertos. Se establecerán, además, rutas aéreas y se fomentará la cooperación en temas de economía digital, inteligencia artificial, computación en la nube y ciudades inteligentes para crear una Ruta de Seda digital. La Iniciativa se financiará a través de un Fondo de la Ruta de Seda, con el apoyo del Banco de Desarrollo de China, el Banco de Exportaciones e Importaciones de China, el Banco Asiático de Inversión en Infraestructura y el Banco de Desarrollo de los países BRICS (Brasil, Rusia, India, China y Sudáfrica), entre otras instituciones (CEPAL, 2018, p. 16).

No hay duda que la Iniciativa FyR constituye, por lo menos en los papeles, una ambiciosa estrategia de desarrollo liderada por el gobierno chino para promover el comercio y la integración económica entre los países participantes a lo largo de rutas marítimas y terrestres, diseñada para mejorar el flujo de factores económicos y la asignación eficiente de recursos. Si bien América Latina no formaba al comienzo explícitamente parte de esa iniciativa, la intención de la política exterior china en América Latina es que esta región soporte la agenda de reforma económica y social de Beijing. La estrategia es, por lo tanto, otro ejemplo de la estrecha vinculación causal entre procesos socio-económicos internos y estrategias de desarrollo exteriores, de un "juego de dos niveles" ("two level game"). Las turbulencias económicas en Estados Unidos y Europa han conducido a una decreciente demanda por mercancías chinas a la cual el gobierno Xi respondió con una nueva concentración al fortalecimiento del consumo interno. Objetivo a largo plazo es bajo el lema de la "nueva normalidad" un crecimiento estable e sustentable. El megaproyecto FyR sirve para compensar las sobrecapacidades internas a través de nuevos megaproyectos en otros países y explorar nuevos mercados para productos chinos. Desde el punto de vista geoestratégico, Bejing reduce a través de la construcción de nuevas vías de transporte terrestres su vulnerabilidad que podría resultar de un posible bloqueo marítimo o el control de las agujas marítimas de las rutas de Malakka y Hornús. Instrumentos centrales de FyR son los programas $1+3+6$ y 3+3, arriba mencionados. Ambos sirven al "upgrade" industrial por estimular un mayor involucramiento de empresas públicas y privadas chinas en sectores "high tech" y manufactureras en América Latina, como, por ejemplo, telecomunicaciones, logística, construcción de trenes y astillero. Los líderes chinos ven estas iniciativas como aportes tanto a sus propios objetivos de desarrollo como a las necesidades de infraestructura en América Latina (MYERS, 2016, p. 32).

Hasta la presente (finales de 2019) ya 19 de 33 países de la región se han incorporado en el megaproyecto y han firmado acuerdos de cooperación con China que podrían favorecer una redirección de la IED hacia las infraestructuras en la región y aportar a un aumento de la productividad, la transferencia de tecnología y el comercio en aquellas empresas y sectores donde se ha implantado (TIMINI; EL-DAHRAW; SÁNCHEZ- 
-ALBORNOS, 2019, p. 4). La centralidad que goza la infraestructura en las actividades de la FyR no es casual porque, primero, las empresas chinas han adquirido a lo largo de los 40 años de la reforma y apertura una rica experiencia en la construcción de infraestructuras, abarcando diversos campos, como gasoductos, centrales eléctricas, carreteras, dragado de puertos, túneles, viviendas, instalaciones de comunicación y ferrocarriles; y segundo, porque la estructura de las exportaciones latinoamericanas con el foco en recursos naturales, productos mineras, petróleo y gas exigen una adecuada infraestructura de transporte. Al lado latinoamericano se espera que la cooperación en el marco de FyR va a promover su desarrollo y levantar la cooperación a un nuevo nivel. Es por eso que los presidentes de Argentina y Chile, Mauricio Macri y Michelle Bachelette, participaron en el Foro de FyR en mayo de 2017 en Beijing y muchos países de la región han firmado entre tantos acuerdos de cooperación industrial con el país asiático.

Según un balance de los tres años de vigencia de la FyR por Wang Yi, los resultados de la Iniciativa FyR ya son respetables. Tuvieron lugar 17 subforos para promover la cooperación mutua en 10 áreas. Los mecanismos de diálogo e intercambio fueron reforzados. Más que 80 proyectos fueron financiados en más que 20 países. Con respecto a la ruta marítima, Beijing ya ha comprado, construido o gestionado 42 puertos en 34 países del mundo, ha invitado más que 800 líderes de partidos políticos y 200 jóvenes líderes de países latinoamericanos a visitar China; ha proporcionado aproximadamente 400 becas para entrenamiento y 200 puestos para el programa master on the job. Fueron además implementados el "Partneriado China- América en Ciencia y Tecnología" y el "Programa de Intercambio China- América Latina de Jóvenes Científicos" (YI, 2018). La conectividad, uno de los objetivos primarios de la FyR fue también valorado positivamente por varios expertos latinoamericanos y la CEPAL, cuya Secretaria Ejecutiva, Alicia Bárcenas, la interpretó como un ejemplo de cómo ampliar la conectividad entre ambos lados con una "visión profunda" y el apoyo de la potencia asiática a la región (FRANJA Y RUTA, 2019). Empresas latinoamericanas pueden participar como socios locales en proyectos chinos en la medida que sus gobiernos forman parte como accionistas, por ejemplo, del AIIB, empresas brasileras porque el gobierno de su país es accionista del Banco de los BRICS (SCHUSTER, 2017, p.3).

Desde el despegue de la Iniciativa FyR, ese proyecto fue acompañado también por voces críticos. Los casos más espectaculares afuera de América Latina fueron ellos de Malaysia y Sri Lanka.

También en América Latina surgió en los últimos años un debate sobre la presencia de China en la región en general, sobre los efectos de la Iniciativa FyR en particular. Este debate tiende a polarizarse entre, por un lado, la mayoría de los gobiernos y los grandes grupos económicos, que ven la oferta china como una oportunidad, una demostración de solidaridad y de profundización de la cooperación Sur-Sur y, al otro

lado, movimientos sociales, ONGs ambientalistas, pueblas indígenas y pequeños empresarios, que ven en todo ello la repetición de la actuación condicionada de EE.UU. y la Unión Europea en el continente. Los primeros subrayan sobre todo el aporte de la FyR al crecimiento econó- 
10. Casos emblemáticos son al respecto la represión contra poblaciones peruanas que se levantaron contra proyectos mineros y en Nicaragua grupos de protesta contra lo planes de un nuevo canal interoceánico. mico registrado gracias a las exportaciones de materias primas, la llegada de capitales abundantes y rápidas para infraestructuras y la reducción de la dependencia del mercado norteamericano, así como el hecho de que China no impone, como por ejemplo la UE y EEUU. condiciones políticas y parece, respetando la soberanía no tener interés en cuestionar el orden político de los países de la región. Adriana Erthal Abdenur y Danilo Marcondes de Souza Neto mencionaron ya en 2013 cuatros riesgos políticos del creciente compromiso económico de China en América Latina: cambios de prioridades temáticas, desplazamiento de donantes, exclusión de la sociedad civil y fragmentación regional (ABDENUR; MARCONDES DE SOUZA NIETO, 2013, p.70). Como efectos negativos son mencionados también la destrucción de la pequeña industria local debido a la competencia de la mano de obra china y la invasión de sus productos a bajo costo, que acelera procesos de desindustrialización; la profundización de la especialización tradicional en productos exportadores, es decir, materias primas y con eso el mantenimiento de una estrategia que se ha mostrado cada vez más como una trampa de desarrollo; el gran costo ambiental, resultado, por ejemplo, de las desforestaciones; gases de efecto invernadero y uso de grandes cantidades de agua que representan muchos proyectos de infraestructura. Efectos dañosos y por eso objeto de crítica son además la acumulación de altas deudas por los créditos chinos; el aumento del cultivo de productos transgénicos y el uso de insumos tóxicos. Voces críticas se refieren también a un aumento considerable de la represión, que ejercen los gobiernos sobre aquellos que cuestionan los proyectos chinos, se movilizan contra ellos y arriesgan ser difamados como "enemigos de la patria" y actuar en contra del bienestar del país ${ }^{10}$. Finalmente se critica en América Latina que los chinos contratan en primer lugar trabajadores chinos en sus proyectos, exportan muchas veces sobrecapacidades de la propia industria de hierro y cemento y que sus proyectos son muchas veces sobredimensionados (NIETO PEREIRA, 2015; RADUNSKI , 2019).

Evaluando la importancia de la FyR para la región después de tres años de su despeje, se puede decir con Adrian Erthal Abdenur y Arie González Levaggi que esa iniciativa es mucho más que una táctica de la política exterior china o una estrategia puramente comercial. Tiende más bien a una conectividad de múltiples tipos y en varias áreas, como ha expresado la Declaración Final del Foro FyR en 2017. Su importancia para América Latina es, por lo tanto, también multi-dimensional e incluye tanto las áreas de comercio, inversiones, cooperación económica, financiamiento y seguridad como el de alianzas políticas, intercambios científicos y culturales (ABDENUR; GONZALEZ LEVAGI, 2018, p. 8.). La Iniciativa FyR vendida por China como Cooperación Sur - Sur parece a abrir un capítulo nuevo del Consenso de Beijing y tiende a ser cada vez más una plataforma normativa de cooperación económica, trasciende las instituciones establecidas como la OMC y puede llevar tanto a nuevas alianzas como nuevas fracturas. La Iniciativa sirve a los líderes chinos también como instrumento para fortalecer, tanto la Regional Comprehensive Partnership (RCE), una respuesta china a la Alianza del Pacífico (AP), como para ampliar el campo de sus relaciones bilaterales con aquellos países que reconocen su "Política Una China" (ABDENUR; GONZALEZ LEVAGI, 2018). 
Con la asunción de Donald Trump al comienzo de 2017, su estrategia "America First" su estrategia de ensimismamiento y su distanciamiento de América del Sur surgió la pregunta si China podría suplir este vacío y apoyar a la región a aumentar su competitividad y mejorar su inserción en la economía internacional. Hay, sin duda, desarrollos que van en esta dirección. Un ejemplo es la política proteccionista, implementado por Trump. Su objetivo central es dejar de vender dentro de Estados Unidos a través de la colocación de un arancel significativo para frenar las exportaciones de China y México hacia Estados Unidos. Esta medida es en realidad un doble autogol. Tiene, por un lado, el efecto del desvío de rutas comerciales, en el caso de la soja, por ejemplo, en favor de Brasil, Argentina y Uruguay. Perjudica, segundo, en primera instancia a las empresas transnacionales - en su mayoría norteamericanas- que son aquellas que establecieron el outsourcing y los mecanismos de comercio bilateral que acabaron en tratados liberales de libre comercio (UGARTECHE, 2016). Tiene, finalmente, el efecto aumentar los precios para los consumidores norteamericanos.

Un segundo ejemplo: La retirada de Estados Unidos del TPP ha llevado a que el presidente chino reafirmó en la reunión del APEC en Lima su llamamiento a impulsar la construcción de una Área de Libre Comercio de Asia-Pacífico, compuesto por 27 países en lugar de 12 del TPP. Este esquema es mucho más ventajoso para los países latinoamericanos que el TPP porque no utiliza el CIADI como el mecanismo de resolución de controversias y no prorroga las marcas y patentes. Tampoco se introducen temas de seguridad en este tratado.. La propuesta de Xi fue aclamada por los participantes y especificada en el documento final de la reunión, la Declaración de Lima. (APEC, 2016).

El interés primordial de América Latina en la relación triangular es como Noesselt y Solis Landivar han constatado con razón, intentar reducir su sobredependencia de EEUU y de sus socios de comercio tradicionales a través de la creación de nuevas instituciones y organizaciones regionales y transregionales que facilitan el pooling de conocimientos y recursos y la reducción de costos de transacción. No obstante, este desarrollo no indica la sustitución de un socio de cooperación (Estados Unidos) por un otro (China), demuestra más bien, que América Latina está adaptando un enfoque multiangular, manteniendo relaciones con una multitud de actores para proteger su autonomía recuperada. Tanto en el caso de China, como de América Latina (ni hablar de EEUU) las interacciones con socios externos son conducidas por intereses nacionales de desarrollo, en el caso de China de acceso a recursos naturales y apoyo para sus intereses en instituciones internacionales, en el caso de América Latina de acceso a créditos, proyectos comunes de infraestructura y transferencia de tecnología, en el caso de EEUU para el objetivo global (y difuso) de su presidente "Make America great again". Si bien los proyectos chinos no afectan directamente a intereses de terceros países, la nueva presencia de compañías e inversores chinos enciende la competencia por mercados y recursos (NOESSELT; SOLIS LANDIVAR, 2013, p.5). 
11. China ocupa, por ejemplo, el segundo lugar en aportes financieros al sistema de las NU, ha apoyado entre 2000 y 2018 no menos que 182 de 190 resoluciones de las $\mathrm{NU}$ y lidera cuatro suborganizaciones de las NU (KAMP, 2020, p.3)
Es evidente, por otro lado, que China todavía necesita a Estados Unidos y está consciente que (todavía) no puede asumir el rol global de Estados Unidos. El país necesita además la globalización para que pueda financiar su crecimiento económico y mantener la estabilidad política en casa, una de las preocupaciones primordiales de la cúpula política china. Xi Jinping se ha presentado en el Foro de Davos en febrero 2017 no en última instancia por eso como nuevo defensor ferviente del libre comercio. En la realidad, sin embargo, China es con sus mercados semi-cerrados todo menos que un modelo del libre comercio y mercado, si bien hay indicios fuertes de una creciente apertura de la economía china a inversiones y co-participaciones extranjeras, también en el sector financiero (REUTERS, 2018).

Una segunda arena en la cual los líderes chinos pueden sacar provecho es el medio ambiente donde Trump está haciendo el trabajo para ellos. Estados Unidos no sigue siendo como durante el gobierno de Barak Obama un promotor al respecto, sino ha dejado este rol justamente a China y con eso a un país que fue considerado durante mucho tiempo como uno de los mayores pecadores del medio ambiente. Liu Zhenmin, embajador chino en las Naciones Unidas ha subrayado la cooperación internacional de su país en esta materia en la Cumbre sobre el clima en Marakesch y reforzado la lealtad de China al acuerdo de Paris. Parece, por lo tanto, un mundo paradojo: China, uno de los países más contaminantes del mundo se está transformando en el protagonista para la salvación del clima, o, como Li Shuo, experto en energía de Greenpeace ha dicho: "China: from cero to hero" (HECKING, 2016).

Una tercera área donde China persigue una política ofensiva con efectos por lo menos indirectos a América Latina y sus relaciones con su socio tradicional Estados Unidos se refiere a la geopolítica. Mientras la potencia líder en Asia fue hasta la presidencia de Xi Jinping más bien cautelosa en reclamar un rol de liderazgo internacional, este comportamiento cambió paso por paso bajo el liderazgo de Xi Jinping. Así, Xi formuló en 2015 el programa industrial "Made in China 2025" con el objetivo, llevar al país a la punta del avance tecnológico en el mundo, y promulgó en febrero 2017 por primera vez una política del "doble liderazgo": Más allá de su liderazgo tecnológico su país "debería conducir la comunidad internacional en la construcción común de un orden mundial más justo y más sensato" (GIESSEN; STRITTMATTER, 2017). En su búsqueda de un rol más protagónico en el ámbito internacional, la potencia asiática se hace cargo además cada vez más responsabilidad en la arena internacional" ${ }^{11}$.

América Latina, durante más de un siglo el patio trasero "natural" de EE.UU. y bajo su tutela, es vista hoy de Xi como un socio en este camino hacia un "doble liderazgo", porque es parte del Sur Global. El momento parece oportuno al respecto porque la región pudo ampliar su margen de maniobra internacional desde la asunción de Trump que ha mostrado poco interés en la región al sur del Rio Grande con la excepción de México (migración, USMCA) y el llamado Triángulo del Norte (Guatemala, El Salvador y Honduras, por las migraciones), Venezuela (por el tipo de régimen, el petróleo y el desastre económico-social) y Colombia ( tráfico de drogas). Este desinterés de la Casa Blanca se articula paradójicamente 
en una coyuntura política donde la ola de gobiernos de centro - izquierda o izquierda que han dominado una década la arena política latinoamericana ha llegada desde los años 2013/14 a su fin y fue reemplazada mayoritariamente por gobiernos de centro-derecha y derecha que apuntan a relaciones más estrechas con los países del Norte que sus antecesores, se ven, sin embargo, frustrados por las medidas proteccionistas de Trump y su amplio desinterés en la región .

Mientras las relaciones de América Latina con Estados Unidos quedan llenas de interrogantes y estratégicamente hasta ahora más bien confusas, la subregión puede esperar durante los años venideros tanto continuidad como cambios en sus relaciones con el gigante asiático. La región al sur del Rio Grande va a mantener, por un lado, su rol como destino de exportaciones manufactureras, inversiones directas y líneas de créditos de China y sigue sirviendo como proveedor importante de materias primas. A pesar del actual debilitamiento de crecimiento en la economía china - en 2019 alrededor del 6\% - este país permanezca la fuerza impulsora dominante por detrás de la creciente demanda energética y por productos agrícolas. Sin embargo, como consecuencia de la "transformación económica" en marcha en China, el traslado de grandes complejos de su industria manufacturera a otros países su demanda por ciertos recursos naturales va a bajar, por otros va a subir como consecuencia de un mayor poder de compra en el mercado interno chino y del desplazamiento creciente de la industria a la provisión de servicios y alta tecnología. Como consecuencia, empresas chinas van a invertir, más allá de los sectores minería, hidrocarburo y agricultura cada vez más en sectores industriales high tech y servicios (ESPINAZA; MARCHAN; SUCRE, 2015).

Mayores inversiones en ciencia e innovación como requisitos de un buen aprovechamiento de la cooperación china

Frente a este rediseño de la estrategia china hacia América Latina surge la pregunta, si su contraparte latinoamericano está realmente preparado al respecto. En un estudio de 2016 el BID ha indagado sobre el impacto de la innovación en tratados comerciales entre China y diez países, tres de ellos latinoamericanos (Chile, Costa Rica y Perú) (CHELALA, 2016). La interconexión entre tratados de comercio e innovación se concreta según este estudio, principalmente en las áreas de cooperación técnica; transferencia de tecnología; investigación, desarrollo e innovación; patentes y propiedad intelectual., Las cifras del BID indican claramente para estas áreas un impacto modesto de esos tratados de comercio en los diez países seleccionados. Eso tiene que ver con el atraso de la región en éstas áreas y el hecho de que como consecuencia de eso la participación de América Latina en las cadenas globales de valor es sustancialmente inferior que la de otras regiones. Por lo tanto, cerrar la brecha tecnológica no será fácil para los gobiernos de la región, pero no parecen haber otra alternativa. Con respecto a la diversificación comercial, sólo Chile, Colombia y Costa Rica están a la altura de China, mientras que el capital de innovación en América Latina es mucho menor que el de la OCDE. Según la Organización Mundial de la Propiedad Intelectual (OMPI), de una 
12. Scimago Institutions Ranking - Latin America - disponible en https://www scimagoj.com/countryrank.php?region=Latin America clasificación que integran 128 países, liderada por Suiza, Suecia y el Reino Unido, sólo un país latinoamericano figuraba, en 2016, entre los primeros cincuenta: Chile, en el puesto 46, seguido por Costa Rica, en el 53; México, en el 58. Les siguen Panamá (63), Colombia (65), Uruguay (67), Brasil (69), Perú (70) y Argentina (76). Bolivia, el último país latinoamericano en el ranking, se sitúa en el lugar 106 (AGENCIA EFE, 2017). En contraste, China se ha convertido en la novena edición del Índice Mundial de Innovación en el primer país de ingresos medios en entrar al selecto grupo de veinticinco países que encabezan (AGENCIA EFE 2017). Aún más elocuente es otro ranking: el de Start Ups. Entre los 494 Start Ups con un valor más que 1 mil millones de dólares, 206 tienen su sede en China, en Estados Unidos 203. En la punta se encuentra Ant Financial, el brazo financiero de Alibaba, en el segundo lugar también un Start Up chino, Bytedance, con su servicio Alipay. Entre 2010 y 2013 fueron constituido cada año solo un Start Up (GIESEN, 2019).

Tomando en cuenta el atraso tecnológico de los países latinoamericanos y la muy modesta participación de sus empresas en la cadenas globales de valor, el cambio de rumbo de la estrategia china hacia América Latina, su priorización de nuevas áreas, más allá del comercio tradicional - recursos naturales versus manufacturas - puede, una vez implementado, ayudar a los socios latinoamericanos salir de la trampa de la maldición de recursos naturales, diversificar su economía y participar más activamente en el comercio internacional. Una condición irrenunciable es al respecto, sin embargo, un sistema educativo y científico altamente desarrollado en ambas áreas claves, Los países de la región son al respecto muy atrasados. Como señala el último informe de la OCDE, basado en los datos de los 64 países participantes en el Programa para la Evaluación Internacional de los Alumnos (PISA, por sus siglas en inglés), la región está abajo de los estándares globales de rendimiento escolar. Sólo México y Argentina superan el promedio en la relación entre la situación económica y rendimiento escolar. Comparando la educación escolar de América Latina con la de China, las diferencias son remarcables en muchos aspectos, en favor del último (VÉLEZ BUSTILLO, 2017). Para mejorar esta situación deplorable, el informe sugiere políticas públicas, como la creación de entornos de aprendizaje exigentes, la participación de padres y comunidades locales, alentar a los alumnos a que aprovechen al máximo las oportunidades educativas y ofrecer un apoyo focalizado para los estudiantes (CEPAL, 2016).

Otro indicador que tiene que ver con el tema de la competitividad es la producción científica de un país. Esa ha, sin duda, crecida durante los últimos años en la región y sigue creciendo, pero continúa rezagada con respecto al promedio mundial, de acuerdo con el Scimago Institutions Rankings (SIR) de España que mide la producción científica, tasas de colaboración internacional, impacto y porcentaje de artículos publicados en revistas de prestigio internacional de las IES de América Latina y el Caribe, España y Portugal ${ }^{12}$. La investigación sigue concentrada en unas pocas universidades, tiene el segundo crecimiento más rápido del mundo después de Asia - aún sigue siendo solo un cuarto por ciento del total mundial. La tasa de impacto de la mayoría de las investigaciones produ- 
cidas en la región está también por debajo del promedio mundial y la visibilidad de la producción científica todavía modesta. Una de las razones por las cuales la producción científica de la región es escasa es que la comunidad de investigadores activos internacionalmente es relativamente pequeña, como también es el porcentaje del PIB dedicado a la investigación (CEPAL, 2016a).

Conclusiones

Hay pocas dudas que la emergencia de un nuevo orden mundial, la globalización descentrada; el auge de la región Asia-Pacífico y el surgimiento de una serie de mega-acuerdos de comercio van a tener impactos en la política de regionalización latinoamericana y reconfigurar las coaliciones de política económica dentro de cada uno de esos países y entre ellos. Sobre sus resultados se puede actualmente solo espectacular. Evidente es, por otro lado, que la mayoría de los gobiernos de la región, hoy de vertiente centro-derecha, están muy interesados en fortalecer la reinserción de sus países en la economía internacional después de años de economías más cerradas bajo sus antecesores del centro-izquierda e izquierda. Como en los primeros años de la década de 90, la apertura económica, la inversión extranjera y los mercados de capitales volverían a hegemonizar en este caso las estrategias de inserción internacional de la región. Eso pasa paradójicamente en un momento histórico, donde el gran hermano del Norte se distancia cada vez más del credo liberal, se ha despedido de su rol como motor y garante del orden económico multilateral y en Europa crece también la fracción anti-globalización.

Todavía es una cuestión abierta si China va a abrir realmente, es decir, más allá de pasos simbólicos sus mercados, es decir, renunciar en el futuro a aranceles proteccionistas y medidas dumping en el sector exportador. Un rol decisivo al respecto va jugar sin duda el tipo de salida de la guerra comercial entre EEUU y China donde hay muy recientemente señales de un cierto descongelamiento (LANZ, 2019). Aún más relevante va ser en el futuro como los líderes chinos van a ser capaz responder de manera constructiva a sus problemas estructurales internas, entre ellos un endeudamiento enorme, el envejecimiento de su población (véase al respecto LEE; MYERS; WU; FU, 2019), grandes ineficiencias y asignaciones equivocadas de recursos, causadas por la ausencia de un sistema de checks and balances por instituciones independientes.

La reacción de los gobiernos latinoamericanos a la victoria de Trump y al galanteo de China fue naturalmente heterogénea y refleja diferencias entre ellos en materia económica, política e ideológica y en el grado de ser afectados por las medidas proteccionistas norteamericanas y las ofertas del dragón asiático. Son en primer lugar los países del Cono Sur que se están viendo obligados a recalcular su política exterior y estrechar sus lazos con países como China que se ha transformado en su discurso oficial en el gran defensor del libre comercio y la globalización (a pesar de sus prácticas proteccionistas) y menos decididamente con Europa, esperando al mismo tiempo que esto no implica resignar su vínculo privilegiado con Washington. El rediseño hacia una triangulación equilibrada 
entre la región, Estados Unidos y China es más fácil para países como Chile y Perú, que ya tienen acuerdos bilaterales de comercio con Estados Unidos que para Brasil y Argentina que lo mismo quieren, se ven, sin embargo, impedidos por el Protocolo de Ouro Preto que prescribe que tratados de libre comercio deben ser negociados por el organismo Mercosur y no por sus países miembros en particular. Si agregamos la fracción de países del eje bolivariano (Venezuela, Bolivia) con un sentimiento antinorteamericano profundo es claro que no se puede esperar a corto y mediano plazo una estrategia de inserción internacional coherente de la región- en una o otra dirección. Para invertir más en educación, desarrollo tecnológico e innovación faltan a los gobiernos latinoamericanos en el contexto actual de bajo crecimiento global, el retiro de capitales del Norte de la región y bajos precios de materias primas los recursos y muchas veces también la voluntad política. En una región, caracterizado por un alto grado de fragmentación, la unificación de posturas comunes sigue brillando por su ausencia. Declaraciones conjuntas contrarias en el marco de la CELAC son, como Alejandro Frenkel ha destacado con razón, al respecto más bien manifestaciones de deseos que la articulación de una política unificada (FRENKEL, 2017, p.6).

Todo eso pasa en un contexto geoeconómico, donde el proceso de acumulación se desplace hacia la región Asia-Pacífico, el peso económico y político de China en la arena internacional sigue creciendo, está emergiendo un sistema tributario chino que socava el pluralismo de las relaciones económicas internacionales y donde Estados Unidos, durante décadas líder del mundo occidental y del orden liberal mundial está perdiendo bajo la presidencia desastrosa de Donald Trump cada vez más en el juego de poder. El mundo G-0, diagnosticado ocho años atrás por Ian Bremmer y citado en nuestra introducción parece hacer lugar a una nueva constelación de potencias, cuyo perfil todavía no es claro, si bien China debería ocupar sin duda una posición destacada en ella. El nuevo contexto geoeconómico va a producir cambios en la competitividad relativa de los eslabones de las cadenas de producción, en los cálculos de rentabilidad de los diferentes sectores de la economía y en los patrones de inserción internacional de las naciones.

América Latina debe optar si la región o por lo menos algunos de sus miembros van a sacar provecho de este desarrollo y progresar hacia una inserción más activa en la economía internacional y un desarrollo sustentable o otra vez quedarse en su rol tradicional como oferente de materias primas que se está evidenciando cada vez más como una trampa de desarrollo. Para que lo primero pasa, es necesario repensar la política comercial en el sentido que esta política debería ser menos ideológica, más realista y pragmática y los perdedores ser identificados y compensados adecuadamente. Pero eso no alcanza. Para aprovechar al máximo la transformación de China y sus ofertas de cooperación, la región debería, más allá del sector educativo, invertir sustancialmente en innovación, en la calidad y la adecuación de las competencias y en subsanar las deficiencias en infraestructura y logística. Necesarias son, además, mejoras regulaciones, instituciones y capacidades de gobierno para desarrollar proyectos rentables, sustentabilidad medioambiental y un mayor compromiso 
con la transparencia y la buena gobernanza. Los gobiernos tienen que crear mecanismos de cooperación estrecha entre el sector productivo y los centros de investigación con apoyo del Estado. Finalmente, las políticas comerciales tienen que ser compatibles con otras políticas y marcos de referencia, internacionalmente acordados como la Agenda de Trabajo Decente de la OIT, la Agenda de Desarrollo Sostenible de 2013 y el Acuerdo de Paris (SCHILLINGER, 2016).

América Latina como el mundo entero se encuentra en años recientes en una fase de transición profunda sin tomar hasta ahora un rumbo claro. Los acontecimientos globales y regionales recientes, la caída brusca de los precios internacionales de materia primas, el fin del ciclo progresista en la región, el estancamiento económico, las nuevas coaliciones regionales e interregionales como BRICS, MIKTA y 1 la G 20, y las negociaciones de nuevos megaacuerdos comerciales son señales de un nuevo período y dividen aguas en los intereses regionales, aumentan la fragmentación intraregional y dificultan estrategias comunes hacia afuera. Estos cambios abren, sin embargo, también nuevas oportunidades, como muestra el documento "Horizonte 2030" de la CEPAL (CEPAL, 2016a).

Si los gobiernos de la región están dispuestos seguir las líneas directrices de este documento y tienen la voluntad política y la capacidad técnico-administrativa y financiera para implementarlas (los desafíos al respecto discuten BATTACHARYA, et al, 2016), la región podría hacer no solo un paso importante hacia una cultura de igualdad y un desarrollo sostenible, sacar provecho duradero de la cooperación estrecha Sur-Sur con su socio China sino también ganar más peso en la arena internacional.

Las nuevas prioridades en la estrategia institucional de cooperación de la potencia asiática con América Latina pueden ayudar a la región progresar en este camino, pero eso solo si los proyectos tomen en consideración también las voces críticas en los estados y sociedades latinoamericanos participantes, y estén basados en los principios de respeto mutuo, la transparencia y ventajas compartidas.

Referencias

ABDENUR, A.; MARCONDES DE SOUZA NIETO,D. La creciente influencia de China en el Atlántico Sur. Revista CIDOB, n.102-103, p.169-197, 2013. Disponible en https://www.cidob. org/articulos/revista_cidob_d_afers_internacionals/102_103/la_creciente_influencia_de_ china_en_el_atlantico_sur. Acceso el: 24 feb. 2018.

ABDENUR, A.; ERTHAL, A.; GONZALEZ LEVAGGI, A., Trans-Regional Cooperation in a Multipolar World: How is the Belt and Road Initiative Relevant for Latin America?. Londres: London School of Economics (LSE), LSE Global South Unit, Working Paper n.1, 16 pag, 2018.

AGENCIA EFE, Evo reitera críticas a la Alianza del Pacífico. El Nuevo Heraldo, 24 de julio 2017. Disponible en: http://www.elnuevoheraldo.com/noticias/mundo/américa-latina/article28652875.html. Acceso el 3 sep. 2017.

APEC. Leaders' Declaration, Lima, 19 November 2016. Disponible en https://www.apec.org/ Meeting-Papers/Leaders-Declarations/2016/2016_aelm.aspx. Acceso el 28 mar. 2017.

ARBACHE, J.; Hecho en China o hecho para China?, CAF, 21 de octubre de 20. Disponible en https://www.caf.com/es/conocimiento/visiones/2019/10/hecho-en-china-o-hecho-para-china/ Acceso el 14 nov. 2020.

ARNSON, C.; MOHR, M.; ROETT, R. (Eds.), Enter the Dragon? China's Presence in Latin America. Washington, DC.: Woodrow Wilson Center (SAIS) Latin American Program and Asian Programm, 2011, pp.18-25, Disponible en: https://www.wilsoncenter.org/sites/default/ files/EnterDragonFinal.pdf. Acceso el 15 sep. 2018. 
BIBLIOTECA DEL CONGRESO NACIONAL DE CHILE. China se integra al Banco Interamericano de Desarrollo, Santiago de Chile, 14 de enero de 2009. Disponible en https://www. bcn.cl/observatorio/asiapacifico/noticias/china-banco-interamericano-del-desarrollo

BREMMER, J. Every Nation for Itself: Winners and Losers in a G- Zero World, London: Portfolio (Penguin Group), 2012.

BUZAN, B. ; LAWSON, G. Capitalism and the emergent world order. International Affairs, $\mathrm{n}$. 90, v. 1, pp.71-91, 2014.

CEPAL Las relaciones económicas y comerciales entre América Latina y Asia-Pacífico: el vínculo con China, Santiago de Chile, 2008, 109 pp. Disponible en: https://www.cepal.org/es/publicaciones/2912-relaciones-economicas-comerciales-america-latina-asia-pacifico-vinculo-china

CEPAL, Perspectivas económicas de América Latina. Hacia una nueva asociación con China, Santiago de Chile, 2016. Disponible en: <http://repsoitorio.cepal.org/bitstream/handle/11362/39535/S1501061_es.pdf?sequence=1>. Acceso el 10 de mayo de 2018.

CEPAL, Horizontes 2013: La iguladad en el centro de desarrollo sostenible. Santiago de Chile, 2016a. Disponible en: http://repositorio.cepal.org/bitstream/handler/11362/40159/4/S1600653_ es.pdf. Acceso el 30 de mayo de 2018.

CEPAL. China apuesta por vínculo estratéguico con América Latina y el Caribe., Santiago de Chile, 25 de mayo de 2015. Disponible en https://www.cepal.org/es/comunicados/china-apuesta-por-vinculo-estrategico-con-America-Latina-y-el-caribe

-CEPAL Ciencia, tecnología e innovación en la economía digital. La situación de América Latina y el Caribe. Segunda Reunión de la Conferencia Ciencia, Innovación y TIC de la Cepal, Santiago de Chile, 2016a, 94 pag .Disponible en http://repositorio.cepal.org/biststream/handle/11362/40530/3/ S1600833_es.pdf.

CEPAL, Explorando nuevos espacios de cooperación entre América Latina y el Caribe y China. Segunda Reunión Ministerial del Foro de la Comunidad de Estados Latinoamericanos y Caribeños (CELAC) y China, CEPAL, Santiago de Chile, 2018.

CESARIN, S. The Relationship between China and Latin America: Realities and Trends. In: ARNSON; MOHR; ROETT (eds); Enter the Dragon? China's Presence in Latin America. Washington, DC.: Woodrow Wilson Center (SAIS) Latin American Program and Asian Programm, 2011, pp.18-25, Disponible en: <https://www.wilsoncenter.org/sites/default/files/EnterDragonFinal. pdf. Acceso el 10.octubre de 2016.

CHELALA, S., The Impact of Trade agreements with China on innovation. Integración Ideas, Washington D.C, 243, BID-INTAL, 2016.

CHINESE ACADEMY OF INTERNATIONAL TRADE AND ECONOMIC COOPERATION et. al., Report on the sustainable Development of Chinese Enterprises Overseas. 2015. Disponible en: <http://www.cn.undp.org/content/china/en/home/library/south-south-cooperation/2015-report-on-the-sustainable-development-of-chinese-enterprise.html. Acceso el 26. de noviembre de 2018 .

ESPINAZA, R.; MARCHÁN, E.; SUCRE, C.G. La nueva ruta de la seda. Patrones emergentes en el comercio de energía y minerales entre Asia y América Latina. Banco Inter-Americano de Desarrollo (BID), Washington, June 2015.Disponible en https://publications.iadb.org/publications/spanish/document/La-nueva-ruta-de-la-seda-Patrones-emergentes-en-el-comercio-de-energ\%C3\%ADa-y-minerales-entre-Asia-y-Am\%C3\%A9rica-Latina.pdf. Acceso el 13 de diciembre de 2016 .

FORO CHINA-CELAC, Plan de Cooperación (2015-2019), 23 de enero de 2019. Disponible en: $<$ https//www.chinacelacforum.org/esp/zywj_4/t1230945.htm>

FRANJA Y RUTA. ESPECIAL II: Foro de la Franja y Ruta presenta oportunidad para que América Latina proponga hoja de ruta en cooperación, dicen expertos. Foro China-CELAC, 26 de abril 2019. Disponible en: <http://www.chinacelacforum.org/esp/zgtlgtgx_2/t1658150.htm. Acceso el 8 de mayo de 2019.

FRENKEL, A. Y ahora, ?quién podrá defendernos? Nueva Sociedad, Febrero 2017. Disponible en http://nuso.org/articulo/y-ahora-quien-podra-defendernos/. Acceso el 30 de marzo de 2017.

FUNDACIÓN BBVA. Las fuentes de crecimiento en Asia, Capital y Crecimiento Nr.8, 2010, 16pp. Disponible en: https://www.fbbva.es/wp-content/uploads/2017/05/dat/08_CyC_2010_web.pdf

GALLAGHER,K., The China Triangle. Latin America's China boom and the Fate of the Washington Consensus. Daily Times, 8 February 2017. Disponible en: <http://dailytimes.com/opinion/08-Febr-17/kevin-gallaghers-the-ch....Acceso el 28 de febrero de 2018. 
GIESEN,CH. Im Land der Einhörner, Süddeutsche Zeitung, p.16, 25 de octubre 2019.

GIESEN, CH., STRITTMATTER, K., Chinesen hört die Signale. Die Führung in Peking glaubt offenbar, dass die Ära Trump der Volksrepublik neue Chancen eröffnet, Süddeutsche Zeitung, , p.7, 3 de marzo 2017.

GILSON, J. New Interregionalism? The EU and East Asia, European Integration, n. 27, v. 3, , p.307-326 September 2005 .

HÄNGGI, H. Interregionalism as a multifaceted phenomen. In: HÄNGGI, H., R. ROLOFF; J. RÜLAND (Eds.). Interregionalism and International Relations, Routlege Avances in International Relations and Global Politics, London, New York, 2006.

HECKING, C., Die rot-grüne Supermacht, Die Zeit, n. 49, 24 November 2016.

HECKING,O.; BALLESTY, M., La competitividad más allá del tipo de cambio: La evidencia para América del Sur. Manuscrito no publicado, CEPAL, Buenos Aires, 2014.

HEINE, J., Marco Polo goes to South America One Belt, One Road due East, CRIES, 15 de mayo 2017. Disponible en https://www.cries.org/?p=3888. Acceso el 10 de noviembre de 2017..

KACEF, BALLESTY. La competitividad más allá del tipo de cambio: La evidencia para América Latina del Sur, Manuscrito no publicado, CEPAL, Buenos Aires 2014.

KAMP, M., Die größte Gefahr ist ein schwaches China, Neue Züricher Zeitung (NZZ), 25 de abril 2020. Disponible en <http://www.nzz.ch/meinung/china-soll-auf-globales-ebene-verantwortung....Acceso el 26 de abril de 2020.

LANZ,M. Die USA und China erzielen im Handelsstreit einen Mini-Deal. Neue Züricher Zeitung (NZZ), 12 de octubre de 2019. Disponible en <https://www.nzz.ch/wirtschaft/die-usa-und-china-erzielen-im-handelsstreit. Acceso el 14 de octubre de 2019.

LEE MYERS, St.; WU, J; FU, C. China's Looming Crisis: A Shrinking Population, The New York Times, January 21, 2019. Disponible en: <https://www.nytimes.com/interactive/2019/01/17/ world/asia/chin...Acceso el 23 de enero de $2019 .$.

MINISTERIO DE RELACIONES EXTERIORES DE LA REPÚBLICA DE CHINA, Texto integro del Documento sobre la Política de China hacia América Latina, Bejing, 5 de noviembre 2008 .

MINISTERIO DE RELACIONES EXTERIORESDE LA REPÚBLICA DE CHINA. Perspectivas y acciones para promover la construcción conjunta de la Franja Económica a lo largo de la Ruta de la Seda y de la Ruta de la Seda Maritima del Siglo XXI, Bejing, 28 de marzo 2015. Disponible en https://www.fmprc.gov.cn/esp/zxxx/t1252441.shtml

MINISTRY OF FOREIGN AFFAIRS. THE PEOPLES REPUBLIQUE OF CHINA, Documento sobre la Política de China hacia América Latina y el Caribe, 24 de noviembre 2016. Disponible en: <https://www.fmpr.gov.cn/esp/wjdt/wjzc/1418256(2016).shml Acceso el 228 de enero de 2018.

MORGENTHAU, H.J., Politics Amang Nations. The Struggle for Power and Peace, New York 1948.

MOSQUERO, M.;MORALES, D., La estrategia institucional de China hacia América Latina. Análisis comparado entre los foros Celac-China y Celac-Unión Europea, Revista OASIS, Nr.28, Julio-Diciembre 2018, pp.123-149. Disponible en: <https://revistas.uexternado.edu.co/ index.php/oasis/article/view/5. Acceso el 20 de mayo de 2019..

MOURON , F.,URDINEZ,F.y SCHIMONI, F. Sin espacio para todos: China y la competencia por el Sur, Revista CIDOB d'AfersInternacionals, 114,pp.17-39. Disponible en http://www.raco. cat/index.php/RevistaCIDOB/article/view/316643/406743.

MÜLLER, H. Internationale Beziehungen als kommunikatives Handeln. Zur Kritik der utilitaristischen Handlungstheorien, Zeitschrift für Internationale Beziehungen 1, 1994, pp. 15-44.

MYERS, M., Can China Make New Friends in LAC? Latin Trade, September 7, 2 pp. Disponible en: <http://www.thedialogue.org/blogs/2016/can-china-make-new - friends...Acceso el 10 de octubre de 2018.

NIETO PEREIRA, L. La Ruta de la Seda en América Latina, La Marea, 5 de junio 2015. Disponible en <http://www.lamarea.com/2015/06/05/la-ruta-de-la-seda-en-america-latina/. Acceso el 23. marzo de 2018 .

NOESSELT, N.; A. SOLIS LANDIVAR. China in Latin America: Competition in the United States ",Strategic Backyard“. GIGA Focus, Nr.7, International Edition, 2013.

OBSERVATORIO deDE LA POLİTICA CHINA. CELAC - CHINA. Plan de Cooperación 
ONUF, N.G., World of Our Making. Rules and Rule in Social Theory and International Relations, Columbia, 1989.

OVIEDO, E.D. Economía de mercado y relación estratégica con China. Análisis preliminar tras la visita de Hu Jintao a la Argentina, Studia Política 9, invierno, 2006.

PAPP, E. China - África: Zonas Económicas Especiales. Observatorio de la política china, 2013. Disponible en: <http:www.politica-china.org/imxd/noticias/doc/1379142399China_y_ las_ZEEs_en_\%C3\%81frica.pdf.. Acceso el 30.de noviembre de 2018.

PORTELLES,Y., China apuesta a alianza estratégica „1+3+6“ con CELAC, enero 2015. Disponible en: <www.andes.info.ec/es/noticias/china-apuesta-alianza-estrategica-136-celac.html.. Acceso el 30 de marzo de 2018.

PRECIADIO CORONADO, J.M. Paradigma social en debate: aportaciones del enfoque geopolítico crítico. La CELAC en la integración autónoma de América Latina. In: RUIZ; URIBE (Coord.). América Latina en la crisis global: Problemas y desafíos, pp.27-49, Ciudad de México: Instituto Universitario Internacional de Toluca (IUIT), Consejo Latinoamericano de Ciencias Sociales (CLACSO) / Asocioción Latinoamericana de Sociología (ALAS)/ Universidad de Tijuana (UDT). Disponible en: <http://www.clacso.org.ar/libreria-latinoamericana/libro_detalle. php?id_libro=880. Acceso el 19 de julio de 2019.

RADUNSKI, M., China first! Das Land will neben Amerika zur zweiten Supermacht werden, in: Neue Züricher Zeitung , 20 de julio 2019. Disponible en: < https://nzzas.nzz.ch/international/ china-die-supermsacht-neben-d.... Accseo el 21 de julio de 2019.

RAMO, J.C. The Bejing Consensus. Notes on the New Physics of Chinese power, Londres, Foreign Affairs Policy Center, 2004.

RAMÓN BERJANO; C., GIRADO. Las crecientes relaciones China-Africa y China- Latinoamérica. In: VELLOSO, M; MALENA;(Comp.), Nuevas estrategias de relacionamiento con la República Popular de China, Buenos Aires, CARI, 2015.

REUTERS. China lanzará nuevas medidas de apertura del mercado este año, 24 de enero de 2018. Disponible en https://de.reuters.com/article/davos-china-idESKBN1FD1VF-OESBS

REYES MATTA, F. Innovación: Eje clave del diálogo futuro China - América Latina. VIII SIMPÓSIO ELECTRÓNICO INTERNACIONAL SOBRE POLÍTICA DE CHINA, 1-21 de marzo 2017, Santiago de Chile, 13 pp. Disponible en: <http://www.asiared.com/es/downloads2/17_ 3-s_reyes-matta.pdf. Acceso el 10 de febrero de $2018 .$.

ROSALES, O., KUWAYAMA, M. China y América Latina y el Caribe. Hacia una relación económica y comercial estratégica, CEPAL, Santiago de Chile, 2012. Disponible en https:// www.redalc-china.org/monitor/images/pdfs/Investigacion/15_Rosales_2012.pdf. Acceso el 20 de marzo de 2019.

SCHILLINGER, H.R., In need of Rethinking. Trade policies in Times of De-Globalization, FES: Dialogue on Gloablization, Bonn, August 2016;

SCHÜLLER, M; SCHÜLLER-ZHOU. Economic Policy in the Time of the Global Financial Crisis: Which Way Out?, Journal of Current Chinese Affais, 38, 3, 2009, pp. 165-181.

SCHUSTER, M. América Latina en la estrategia económica china. Entrevista a Gustavo Girado. Nueva Sociedad, Noviembre 2017. Disponible en: $<$ https://nuso.org/artriculo/america-latina-en-la-estrategia-economica..Acceso el 16 de enero de 2018.

SEVARES, J. China, Un socio imperial para Argentina y América Latina, Buenos Aires: egahasa, 2015, $208 \mathrm{pp}$.

SHIRK, S. F. China: Fragile Superpower; New York: Oxford University Press, 2007.

STEWART, P. The Unruled World: The Case for Good Enough Global Governance, Foreign Affairs, v. 93, n. 1, pp.58-73, 2014 Disponible en: <https://www.foreignaffairs.com/articles/ 2013-12-06unruled-world. Acceso el 27.de marzo de 2018.

TIMINI, J; EL DAHRAWY; SANCHEZ-ALBORNOZ. El impacto de China sobre América Latina: los canales comerciales y de inversión extranjera directa. Boletín Económico 2, 17 de mayo 2019.

UGARTECHE, O. Trump en América Latina. Sin grandes cambios. Mexico, 2016, Clacso. Recuperado de: https://www.clacso.org.ar/megafon/images/megafon10/pdf/Megafon_10_2_Oscar_Ugarteche.pdf. Acceso el 20.de april de 2018.

VALENZUELA ÁLVAREZ, J.L. Evaluación de la Política Exterior de China para América Latina. Relaciones Internacionales, n.53, 2017, p.115-133. Disponible en: <https://revistas-unip. edu.ar/RRII-IRI/article/download/..../Acceso el 28 de noviembre de 2017.. 
VELEZ BUSTILLO, E. What makes good schools? The case of China and LAC. PREAL blog, january 27 2017. Disponible en: <http://www.thedialogues.org/blogs/2017/01/what-makes-good-school...Acceso el 15 de febrero de 2017.

WALTZ, K.N. Theory of International Politics, Long Grove Il: Waveland Press 1979.

WENDT, A. Social Theory of International Politics, Cambridge: Cambridge University Press, 1999.

WOERTZ, E. (Ed.), Reconfiguration of the Global South. Africa and Latin America and the Asian Century. Abington: Routledge, 2016.

XINHUA. Como puede China alimentar a su enorme población de $1.400 \mathrm{M}$ de personas?,América Economía, 17 de septiembre de 2019. Disponible en https://www.americaeconomia.com/ negocios-industrias/como-puede-china-alimentar-su-enorme-poblacion-de-1400m-de-personas. Disponible en <https://thenassauguardian.com/2018/01/17/time-for-closer-partnership-and-greater-cooperation-through-the-china-celac-forum. Acceso el 18 de noviembre de 2020.,

YI,W., Time for closer partnership and greater cooperation through the China-CELAC Forum, The Nassau Guardian, January 17, 2018. /Acceso el 3 de febrero de 2018.. 